\title{
Behaviour of Grain Separation in Thai Transverse Axial Threshing Units for Chainat 1 Rice Varity
}

\author{
Somchai Chuan-udom ${ }^{1,2}$ \\ 1 Department of Agricultural Engineering, Faculty of Engineering, Khon Kaen University, Khon Kaen, \\ 40002, Thailand \\ 2 Applied Engineering for Important Crops of the North East Research Group, Khon Kaen University, \\ Khon Kaen, 40002, Thailand \\ E-mail: somchai.chuan@gmail.com
}

\begin{abstract}
A transverse axial threshing unit is widely used in self-propelled combine harvesters in Thailand and the ASEAN region. The grain separating behaviour of this threshing unit affects the performance of the threshing unit and cleaning unit. This study aims to find out the behaviour of grain separation in a Thai transverse axial flow threshing unit. The concave rod clearance was chosen as the test medium, as this significantly affects the behaviour of grain separation and Chainat 1 rice variety was chosen for test. The results show that $70-80 \%$ of grain were separated from the straw, and then fell through the lower concave of the feeding zone into the cleaning unit; whilst the rest were threshed in the separation zone. The purity of grain input into the cleaning unit was quite steady in the feeding zone, although the grain purity in the separation zone decreased as the length of the separation zone increased. The cumulative straws increased linearly during the feeding zone, as they increased exponentially in the separation zone. In contrast, the cumulative undeveloped kernels and other contaminants increased linearly when the length of the separation zone also increased.
\end{abstract}

Keywords: Axial flow threshing, concave, grain separation, combine harvester.

ENGINEERING JOURNAL Volume 19 Issue 5

Received 11 February 2015

Accepted 11 May 2015

Published 31 October 2015

Online at http://www.engj.org/

DOI:10.4186/ej.2015.19.5.155 


\section{Introduction}

In Thailand, a transverse axial threshing unit is widely used in self-propelled combine harvesters, especially concerning rice production. It is also modified to thresh corn, soybean, sunflower, etc. When using a threshing unit, threshing and separating grain can be completed simultaneously. The unit can be modified and assembled within small-sized combine harvesters to enable suitable working conditions in Thailand, and in other ASEAN countries [1]. Due to its popularity in this region, it is called the Thai combine harvester (Fig. 1).

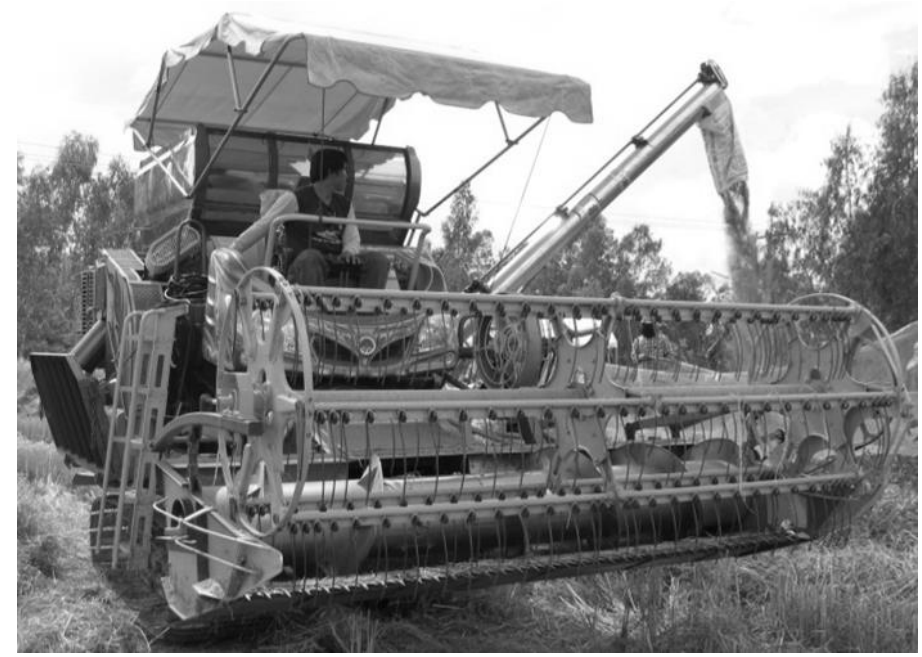

Fig. 1. A Thai combine harvester.

The threshing unit is an important part of the machinery, which affects harvesting losses and the capacity of a combine harvester. The characteristics of the threshing unit of a Thai combine harvester are different from other axial threshing units. For an axial threshing unit, materials are fed from one side and flow axially to the other (Fig. 2). For a transverse axial threshing unit, there are 3 zones: 1 ) the feeding zone, which is $1 / 3$ of the length of the threshing unit, 2) threshing, as the main intent, and 3) the separation zone. Materials are fed from the side of the threshing unit at the feeding zone, and straw is thrown out from the straw discharge channel at the side of the threshing unit, using a threshing rotor which is attached to a rasp bar and separating blade (Fig. 3). For the Thai transverse axial threshing unit, the working principal is similar to a transverse axial threshing unit, but there are only 2 zones: the feeding and separation zones. The lengths of feeding and separation zones are nearly equal; approximately half the length of the threshing unit. After completing the separation zone, the straw is discharged through the straw discharge channel, using a threshing rotor with spiked teeth (Fig. 4).

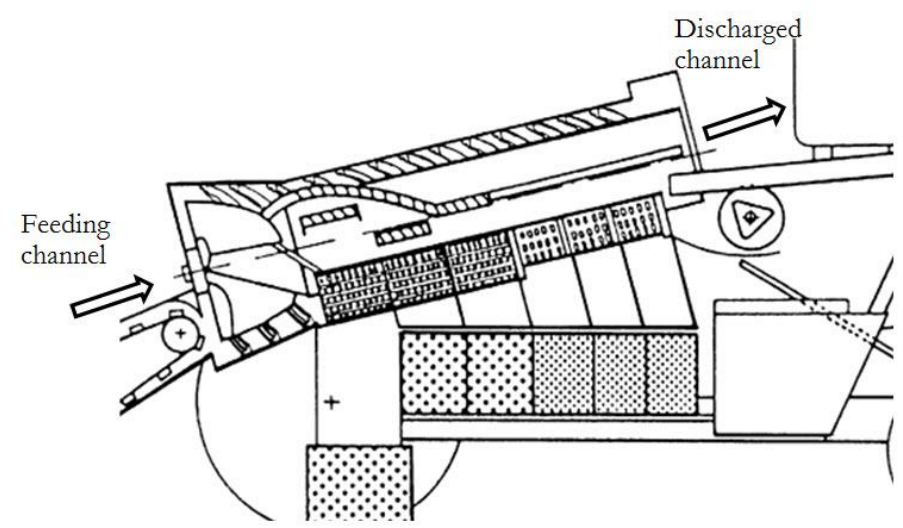

Fig. 2. Axial threshing unit [2]. 


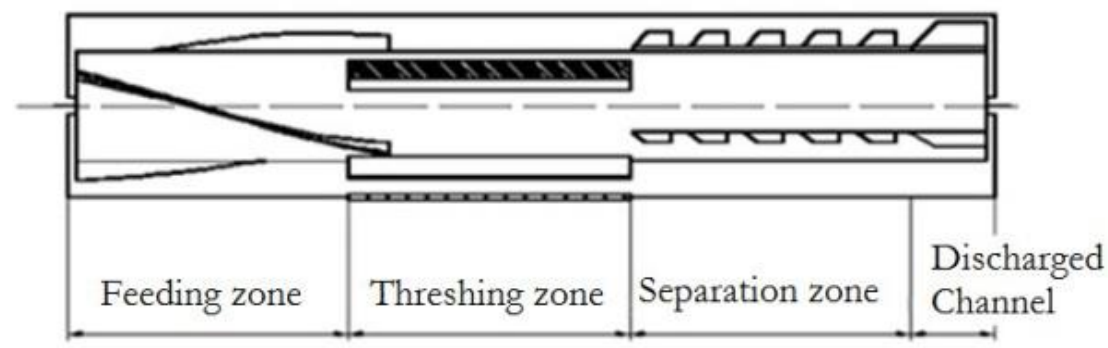

Fig. 3. Transverse axial threshing unit [2].

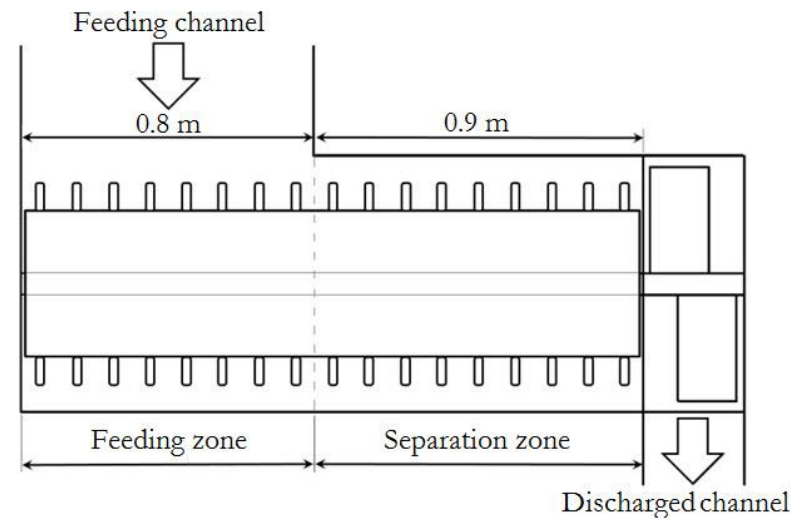

Fig. 4. Thai transverse axial threshing unit.

Former researches concerning Thai transverse axial threshing units have primarily focused upon operating factors and thresh unit design. Chuan-udom and Chinsuwan [3] studied about operating factors of Thai axial rice combine harvesters pertaining to thresh unit losses concerning Thai Hommali rice, and they found that guide vane inclinations, rotor speeds, feed rates, grain moisture content and grain to material other than grain ratio all have an effect upon losses. Chuan-udom and Chinsuwan [4] found that concave rod clearance had the greatest effect upon threshing unit losses of Thai axial rice combine harvesters, followed by side concave clearance, concave clearance, and upper concave clearances combined, respectively. The numbers of spiked teeth, rotor diameters, and the heights of spiked teeth all displayed relatively low losses.

Gummert et al. [5] conducted a study on a transverse axial rice thresher and found that the rotor speeds, feed rates and guide vane inclinations all affected threshing unit losses, and that rotor speed affects grain breakage, yet the feed rates and guide vane inclinations did not cause any grain breakage. Kradangnga et al. [6] observed the effects of rotor speeds and feed rates in a study about the performances of a 4 feet length transverse axial thresher for rice. An increase in rotor speed directly reduced threshing losses and increased grain breakage due to higher impact forces, and yet an increase in feed rate raised the threshing loss, but did not statistically affect grain breakage. Singhal and Thierstein [7] studied the potential for a transverse axial thresher with multi-cropping, and the results showed that it could thresh sorghum, millet, chickpeas, pigeon-peas, wheat and paddy, with more than 95\% efficiency and a grain output of $500-800 \mathrm{~kg} / \mathrm{h}$.

A study of operating factors of a Thai axial thresher affecting corn shelling losses by Chuan-udom [8] reported that guide vane inclination and grain moisture content affected shelling losses, whereas rotor speed, feed rate and grain to material, other than grain ratio, did not significantly affect such losses. Increasing the guide vane inclination or decreasing grain moisture content tended to reduce those losses.

A Thai transverse axial threshing unit has 2 main components: 1) the rotor, and 2) the concave (Fig. 5). The rotor is a hollow metal cylinder attached with spiked teeth. The concave consists of upper and lower concaves. The upper and lower concaves are made of spaced iron rods which are aligned to the concave bar. Spaced guide vanes are attached to upper concave to control the material flow, and the lower concave performs as a thrashing bed using a rotor and grain separator. The grain that separates from the straw falls through the lower concave into the cleaning unit, and thus the grain separation characteristics affect the performance of the cleaning unit. If the behaviour of the transverse axial threshing unit is known, then the cleaning unit can be designed for optimum performance. Consequently, the threshing and cleaning 
performance can be increased. However, there is no study concerning the threshing behaviour of such a threshing unit, and so this study aims to study the behaviour of grain separation in a transverse axial flow threshing unit.

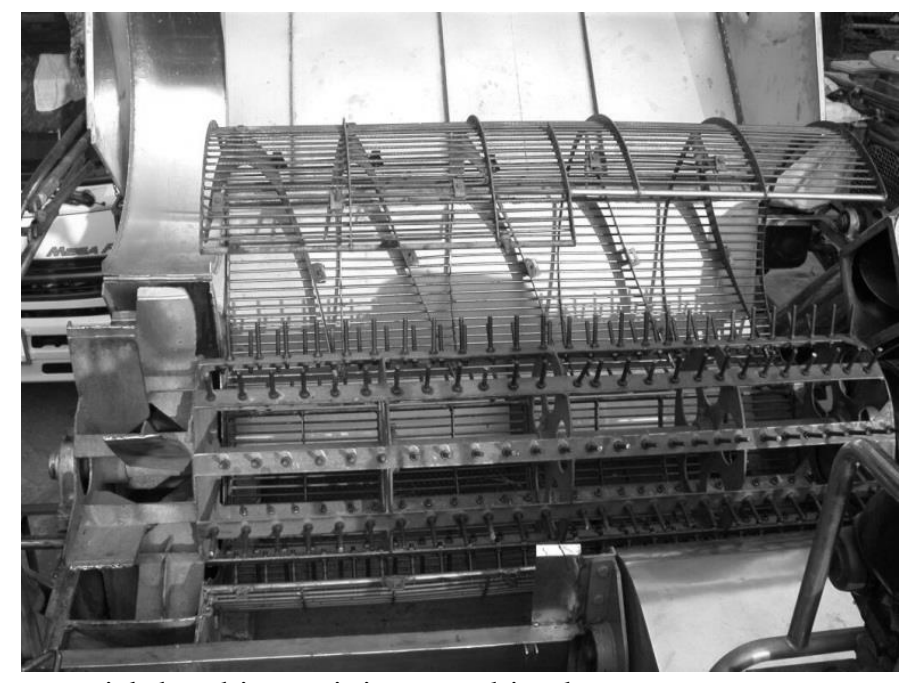

Fig. 5. A Thai transverse axial threshing unit in a combine harvester.

\section{Materials and Methods}

\section{Transverse Axial Threshing Tester}

Laboratory experiments were completed using a Thai transverse axial threshing tester (Fig. 6). The transverse axial threshing unit was $1.7 \mathrm{~m}$ length, and the rotor diameter measured from the tip of the spiked teeth was $0.7 \mathrm{~m}$. The spiked teeth were made of iron rods (11 $\mathrm{mm}$ in diameter and $80 \mathrm{~mm}$ length), with 77 $\mathrm{mm}$ spiked tooth spacing. There were 10 iron strips on the rotor to attach the spiked teeth, and the strips attached comprised 21 and 22 spiked teeth alternately. The total number of spiked teeth was 215 teeth. The upper and lower concave was made of $8 \mathrm{~mm}$ diameter iron rod with $17 \mathrm{~mm}$ spacing. The concave clearance was $10 \mathrm{~mm}$, and five guide vanes were attached to the upper concave with a 70 degree inclination from the rotor axis. The straw discharged blade was $0.27 \mathrm{~m}$ length, and the rotor speeds and feed rates could be varied through the use of an electric motor controller.

Seventeen trays were placed under the lower concave, and along the length of the threshing unit. Each tray was $10 \mathrm{~cm}$ in width. The first to eighth tray $(0-0.8 \mathrm{~m})$ collected the threshed grain from the feeding zone, whilst the 9th to 17th tray $(0.8-1.7 \mathrm{~m})$ collected the threshed grain from the separation zone (Fig. 4).

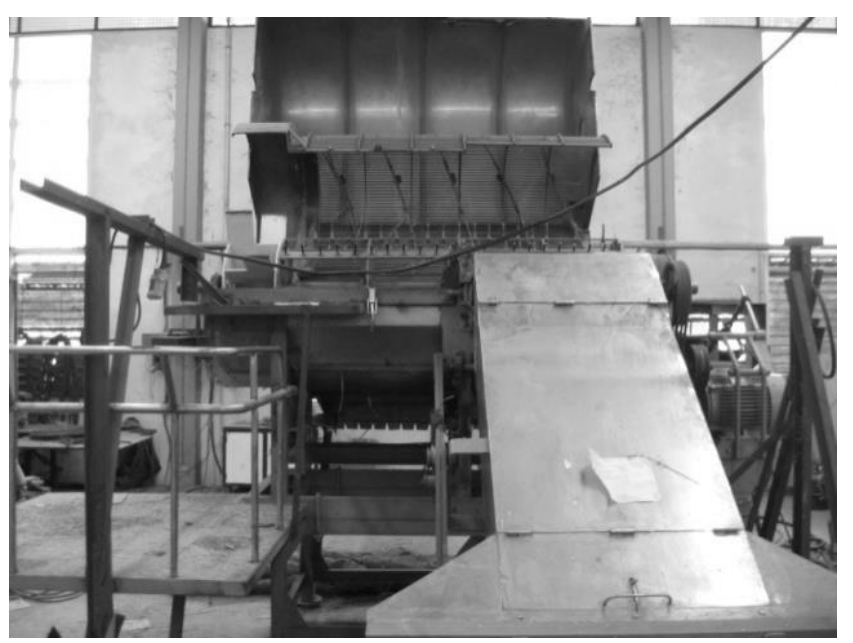

Front view 


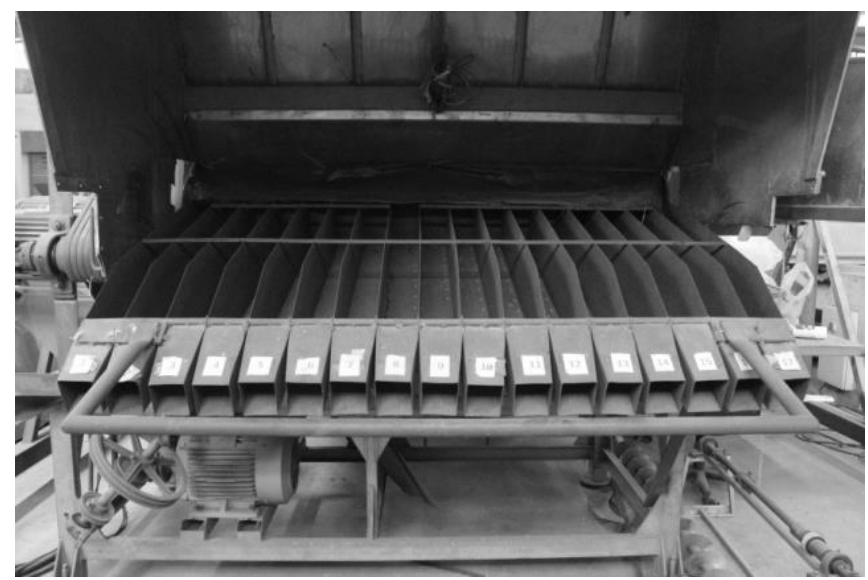

Rear view

Fig. 6. A Thai transverse axial threshing tester.

\section{Experiment Materials and Conditions}

Chainat 1 rice variety, harvested from an irrigation area of Khon Kaen province, Thailand, was used for the experiment. This variety is widely used in Thailand, and has a high thresh loss [9]. The harvested rice was covered by sacks with water spraying in order to maintain the moisture content of the grain and straw during transporting from field to laboratory. The moisture content of the grain and straw were $29.0 \% \mathrm{wb}$ and $65.1 \% \mathrm{wb}$, respectively, and the average stalk length was $0.59 \mathrm{~m}$. The average grain to straw ratio was 0.51 , when the feed rate was $16 \mathrm{~T} / \mathrm{h}$. The tangential rotor speed was set at $20 \mathrm{~m} / \mathrm{s}$, and the concave rod clearance was chosen as the test parameter, as this significantly affects the behaviour of grain separation [4]. The concave rod clearance was varied between 5 levels, namely: 10, 15, 20, 25 and $30 \mathrm{~mm}$, respectively.

\section{Experimental Method}

Each test was completed in 3 replications. $50 \mathrm{~kg}$ of harvested stalks were fed into the threshing unit in each replication, and the threshing output and performances were evaluated for 10 seconds during a steady state of operation. The disposal materials at the straw outlet were collected in a mesh bag, and separated in order to find any lost grain. The output materials that fell through the lower concave were collected in 17 trays, and the materials from each tray were separated, so as to find the amount of grain, straw, dust and other substances.

\section{Results and Discussion}

\section{Cumulative Separated Grain under the Lower Concave}

Cumulative separated grain that passed through the lower concave into the cleaning unit, within the feeding zone (0-0.8 $\mathrm{m}$ of threshing unit length), increased linearly as the threshing length increased (Fig. 7). The linear regression equations when the concave rod clearance varied between 10 and $30 \mathrm{~mm}$ with $\mathrm{R}^{2}=$ 0.9911-0.9988 are shown in Table 1. The results show that the separated grains per length of threshing unit were constant, along the feeding zone. Since $70-80 \%$ of separated grains were accumulated in the feeding zone. This denotes that most of the grains were separated within the first zone of threshing, whilst the rest of the $20-30 \%$ were separated into the separation zone (0.8-1.7 $\mathrm{m}$ of threshing unit length). In this zone, the separated grains under the lower concave decreased exponentially when the length of the concave increased. Therefore, the inverse exponential equation was chosen to describe the threshing behaviour within this zone, as shown in Fig. 8. The $\mathrm{R}^{2}$ values were 0.9989-0.9998 when the concave rod clearance varied between 10 to $30 \mathrm{~mm}$ (Table 2). After the feeding zone, there was no more input material, so the residual grains fell through the concave more easily. Such threshing behaviour was similar to those of an axial threshing unit, but differed from most tangential threshing units which had steady flow of grain along their units $[2,10]$. Referring to the results; the cumulative separated grain could be represented by equations 1 and 2 , for the feeding zone threshing and the separation zone threshing, respectively. 


$$
\begin{gathered}
\mathrm{CS}_{\mathrm{f}}=\mathrm{Ax} \text { (feeding zone) } \\
\mathrm{CS}_{\mathrm{s}}=1-\left(\mathrm{Be}^{\mathrm{Cx}}\right)^{-1} \text { (separation zone) }
\end{gathered}
$$

where $\mathrm{CS}_{\mathrm{f}}=$ Cumulative separated grain in feeding zone (decimal); $\mathrm{CS}_{\mathrm{s}}=$ Cumulative separated grain in separation zone (decimal); $\mathrm{x}=$ Threshing length $(\mathrm{m}) ; \mathrm{A}, \mathrm{B}$ and $\mathrm{C}=$ Constant coefficients that depend upon the varieties and maturity of cereals, and the design and functional parameters of the threshing unit.

In this study, the cumulative separated grain behaviour of the Thai transverse axial threshing unit applied was different from those proposed by Miu and Kutzbach [2]; primarily because the length of the feeding zone in the threshing unit was more than half the total length of the threshing unit itself, which consequently operated in the form of tangential threshing. As a result, the cumulative separated grain analysis within the feeding zone and the separation zones should be evaluated separately, in order to accumulate prediction accuracies.

Referring back to the cumulative separation of grain behaviour; the cleaning unit under the feeding zone of the threshing unit might be overloaded, due to large amounts of input. To avoid this problem, the cleaning unit should be modified to spread grain from the area under the feeding zone into the separation zone.

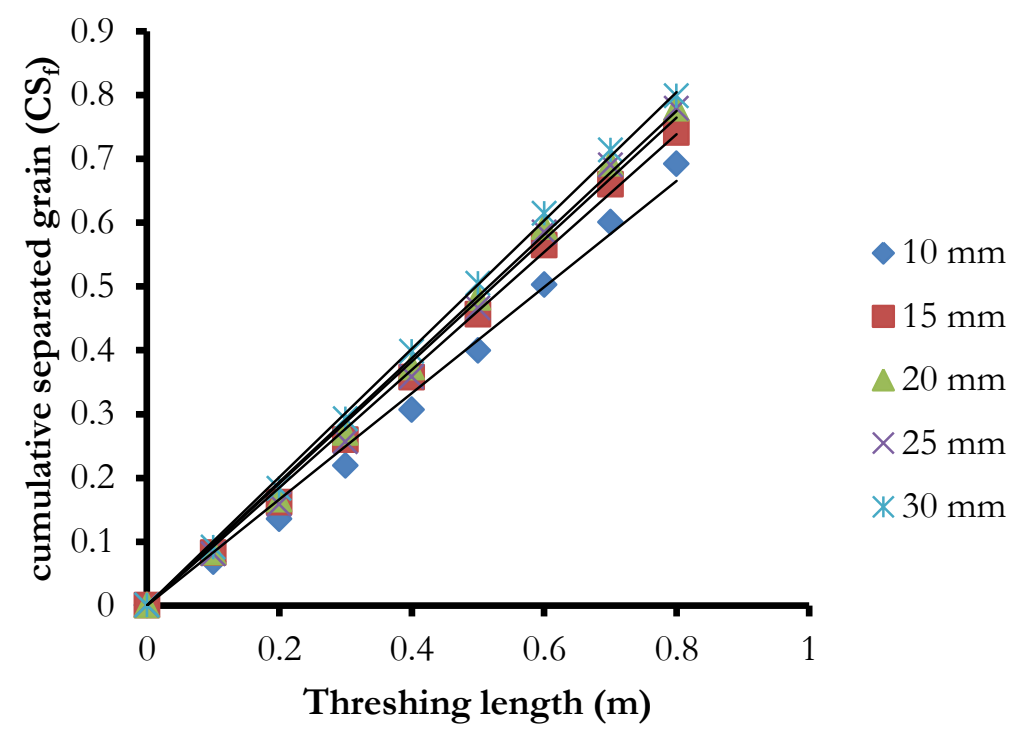

Fig. 7. Behaviour of cumulative separated grain in the feeding zone of a transverse axial threshing unit.

Table 1. Regression equations represented by the cumulative grain, under the lower concave in the feeding zone.

\begin{tabular}{ccc}
\hline Concave rod clearance $(\mathrm{mm})$ & Equation & $\mathrm{R}^{2}$ \\
\hline 10 & $\mathrm{CS}_{\mathrm{f}}=0.8322 \mathrm{x}$ & $\mathrm{R}^{2}=0.9911$ \\
15 & $\mathrm{CS}_{\mathrm{f}}=0.9232 \mathrm{x}$ & $\mathrm{R}^{2}=0.9974$ \\
20 & $\mathrm{CS}_{\mathrm{f}}=0.9691 \mathrm{x}$ & $\mathrm{R}^{2}=0.9968$ \\
25 & $\mathrm{CS}_{\mathrm{f}}=0.9559 \mathrm{x}$ & $\mathrm{R}^{2}=0.9939$ \\
30 & $\mathrm{CS}_{\mathrm{f}}=1.0059 \mathrm{x}$ & $\mathrm{R}^{2}=0.9988$ \\
\hline
\end{tabular}




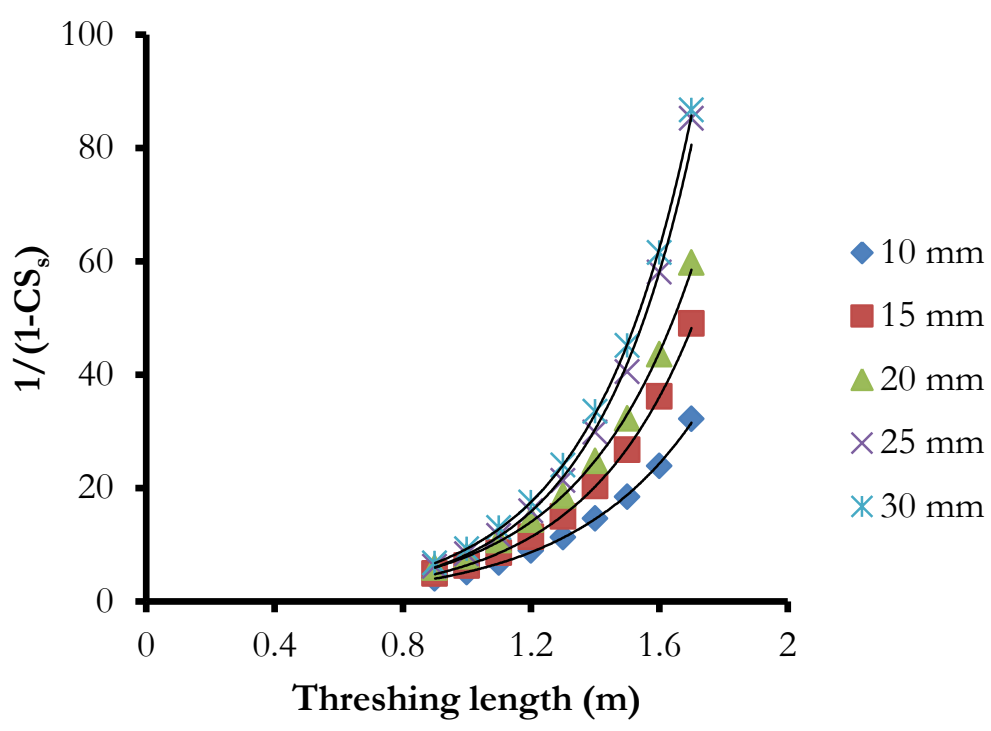

Fig. 8. Behaviour of cumulative separated grain in the separation zone of a transverse axial threshing unit.

Table 2. Regression equations represented by the cumulative grain under the lower concave in the separation zone.

\begin{tabular}{ccc}
\hline Concave rod clearance $(\mathrm{mm})$ & Equation & $\mathrm{R}^{2}$ \\
\hline 10 & $\mathrm{CS}_{\mathrm{s}}=1-\left(0.3922 \mathrm{e}^{2.5805 x}\right)^{-1}$ & $\mathrm{R}^{2}=0.9994$ \\
15 & $\mathrm{CS}_{\mathrm{s}}=1-\left(0.3556 \mathrm{e}^{2.8879 \mathrm{x}}\right)^{-1}$ & $\mathrm{R}^{2}=0.9997$ \\
20 & $\mathrm{CS}_{\mathrm{s}}=1-\left(0.4565 \mathrm{e}^{2.8551 \mathrm{x})}-\mathrm{R}^{-1}\right.$ & $\mathrm{R}^{2}=0.9996$ \\
25 & $\mathrm{CS}_{\mathrm{s}}=1-\left(0.3217 \mathrm{e}^{3.249 x}\right)^{-1}$ & $\mathrm{R}^{2}=0.9989$ \\
30 & $\mathrm{CS}_{\mathrm{s}}=1-\left(0.3887 \mathrm{e}^{3.1744 x}\right)^{-1}$ & $\mathrm{R}^{2}=0.9998$ \\
\hline
\end{tabular}

\section{Grain Purity under the Lower Concave}

The purity of the grain that fell through the lower concave into the feeding zone was higher than $90 \%$. That purity was high and quite constant along the length of the threshing unit. The rice stalks were thrashed steadily in this feeding zone, yet when the stalks were in the separation zone until disposal, at the straw outlet, the purity decreased when the threshing length increased. This behaviour occurred because most of the grain was separated at the feeding zone, and only $20-30 \%$ of the grain was left amongst the larger amounts of straw and other materials in the separation zone. Thus, there was a high possibility that other materials would fall down and be mixed within the grain in this zone. Consequently, the grain purity decreased along threshing unit length, and the grain purity under the lower concave was represented by a $3-$ degree polynomial equation (Eq. 3). The regression equation had an $\mathrm{R}^{2}$ value between 0.9764-0.9944 when the concave rod clearance was varied between 10 to $30 \mathrm{~mm}$, as shown in Fig. 9 and Table 3:

$$
\mathrm{GP}=\left(\mathrm{Dx}^{3}+\mathrm{Ex}^{2}+\mathrm{Fx}\right)^{-1}
$$

where GP = Grain purity (decimal); $\mathrm{x}=$ Threshing length $(\mathrm{m}) ; \mathrm{D}, \mathrm{E}$ and $\mathrm{F}=$ Constant coefficients that depend upon the varieties and maturity of cereals, and the design and functional parameters of the threshing unit.

Any increase in concave rod clearance made the grain purity decrease rapidly. After that, the concave functions of the threshing bed and the filtering sieve, at that same time, caused any adulterated substances to fall down and become mixed with the grain more easily, especially in the case of larger concave rod clearances [11]. 


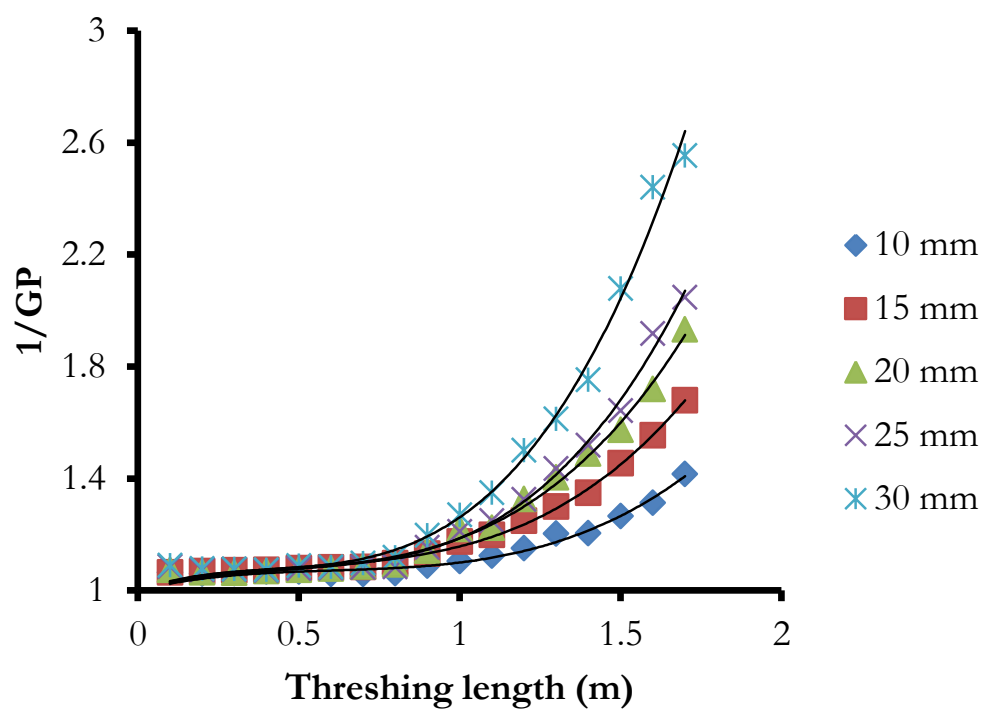

Fig. 9. Behaviour of grain purity in a transverse axial threshing unit.

Table 3. Regression equations represented by the grain purity under a lower concave in the separation zone.

\begin{tabular}{ccc}
\hline Concave rod clearance $(\mathrm{mm})$ & Equation & $\mathrm{R}^{2}$ \\
\hline 10 & $\mathrm{GP}=\left(0.2252 \mathrm{x}^{3}-0.4071 \mathrm{x}^{2}+0.2813 \mathrm{x}+1\right)^{-1}$ & $\mathrm{R}^{2}=0.9764$ \\
15 & $\mathrm{GP}=\left(0.3038 \mathrm{x}^{3}-0.4734 \mathrm{x}^{2}+0.3266 \mathrm{x}+1\right)^{-1}$ & $\mathrm{R}^{2}=0.9944$ \\
20 & $\mathrm{GP}=\left(0.3652 \mathrm{x}^{3}-0.4841 \mathrm{x}^{2}+0.3045 \mathrm{x}+1\right)^{-1}$ & $\mathrm{R}^{2}=0.9928$ \\
25 & $\mathrm{GP}=\left(0.4865 \mathrm{x}^{3}-0.68 \mathrm{x}^{2}+0.3798 \mathrm{x}+1\right)^{-1}$ & $\mathrm{R}^{2}=0.9924$ \\
30 & $\mathrm{GP}=\left(0.6787 \mathrm{x}^{3}-0.8256 \mathrm{x}^{2}+0.4073 \mathrm{x}+1\right)^{-1}$ & $\mathrm{R}^{2}=0.9913$ \\
\hline
\end{tabular}

In the trays under the lower concave, the cumulative straw increased linearly during the feeding zone. However, it increased rapidly in the separation zone, especially when the concave rod clearance was large, as shown in Fig. 10. More straw fell down at the larger concave rod clearance, and this straw significantly influenced the cleaning performances [12], because most of the straw was in larger pieces within the feeding zone, and could not fall through the lower concave. When the materials were thrown into the separation zone, the straw was crushed into smaller pieces, and then easily fell down through the lower concave into the required zone. The amount of straw under the lower concave could be represented by a 2-degree polynomial equation (Eq. (4)). The regression equation has an $\mathrm{R}^{2}$ value between 0.9953-0.9988, when the concave rod clearance is varied between 10 and $30 \mathrm{~mm}$, as shown in Table 4:

$$
\mathrm{SS}=\mathrm{Gx}^{2}+\mathrm{Hx}
$$

where SS = Cumulative separated straw (\%); $\mathrm{x}=$ Threshing length (m); $\mathrm{G}$ and $\mathrm{H}=$ Constant coefficients that depend upon the varieties and maturity of cereals, and the design and functional parameters of the threshing unit. 


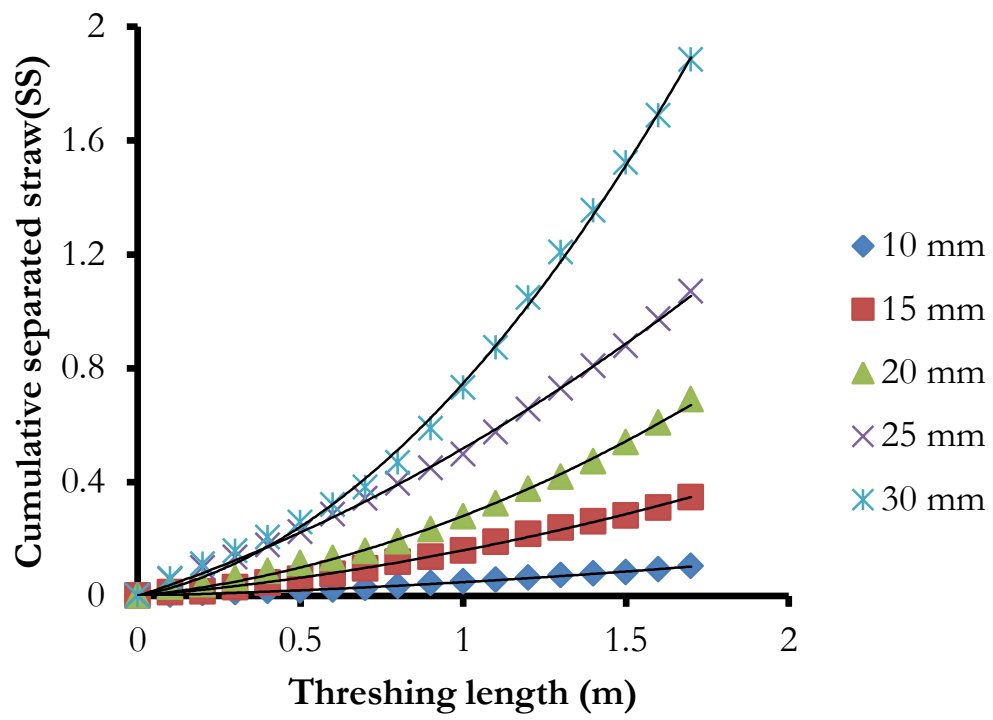

Fig. 10. Behaviour of cumulative separated straw in a transverse axial threshing unit.

Table 4. Regression equations represented by the cumulative straw under the lower concave, in the separation zone.

\begin{tabular}{ccc}
\hline Concave rod clearance $(\mathrm{mm})$ & Equation & $\mathrm{R}^{2}$ \\
\hline 10 & $\mathrm{SS}=0.0002 \mathrm{x}^{2}+0.0031 \mathrm{x}$ & $\mathrm{R}^{2}=0.9953$ \\
15 & $\mathrm{SS}=0.0006 \mathrm{x}^{2}+0.0096 \mathrm{x}$ & $\mathrm{R}^{2}=0.9977$ \\
20 & $\mathrm{SS}=0.00016 \mathrm{x}^{2}+0.0119 \mathrm{x}$ & $\mathrm{R}^{2}=0.9974$ \\
25 & $\mathrm{SS}=0.0014 \mathrm{x}^{2}+0.0374 \mathrm{x}$ & $\mathrm{R}^{2}=0.9988$ \\
30 & $\mathrm{SS}=0.0052 \mathrm{x}^{2}+0.0225 \mathrm{x}$ & $\mathrm{R}^{2}=0.9976$ \\
\hline
\end{tabular}

Considering the amount of immature kernels and other adulterated substances in the trays under the lower concave (Fig. 11), the cumulative amount increased linearly during the feeding zone and the separation zone. This behaviour differed from those of straw, as the undeveloped kernels and other adulterated substances were originally small in size, and could fall through the lower concave along the length of the threshing unit. The amounts of undeveloped kernels and other substances, under the lower concave, can be represented by a linear equation (Eq. (5)). The regression equation has an $\mathrm{R}^{2}$ value between 0.9948-0.9966 when the concave rod clearance was varied between 10 and $30 \mathrm{~mm}$, as shown in Table 5 .

$$
\mathrm{SD}=\mathrm{Kx}
$$

where SD = Cumulative undeveloped kernel and other adulterated substance (\%); $\mathrm{x}=$ Threshing length $(\mathrm{m}) ; \mathrm{K}=$ Constant coefficients that depend upon the varieties and maturity of cereals, and the design and functional parameters of the threshing unit. 


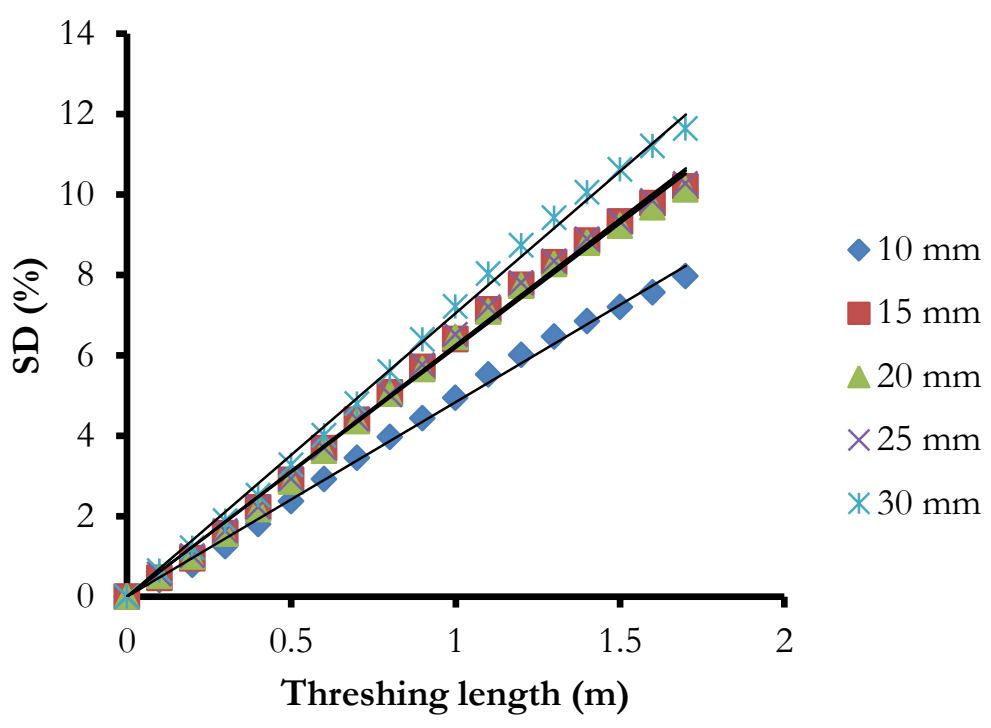

Fig. 11. Behaviour of cumulative undeveloped kernels and other adulterated substances, in a transverse axial threshing unit.

Table 5. Regression equations represented by the cumulative undeveloped kernels and other substances under the lower concave within the feeding zone and the separation zone.

\begin{tabular}{ccc}
\hline Concave rod clearance $(\mathrm{mm})$ & Equation & $\mathrm{R}^{2}$ \\
\hline 10 & $\mathrm{SD}=4.8423 \mathrm{x}$ & $\mathrm{R}^{2}=0.9964$ \\
15 & $\mathrm{SD}=6.2311 \mathrm{x}$ & $\mathrm{R}^{2}=0.9953$ \\
20 & $\mathrm{SD}=6.1878 \mathrm{x}$ & $\mathrm{R}^{2}=0.9948$ \\
25 & $\mathrm{SD}=6.2653 \mathrm{x}$ & $\mathrm{R}^{2}=0.9956$ \\
30 & $\mathrm{SD}=7.0562 \mathrm{x}$ & $\mathrm{R}^{2}=0.9966$ \\
\hline
\end{tabular}

\section{Conclusions}

This paper has studied behaviour of grain separation in a Thai transverse axial flow threshing unit, the following conclusions can be drawn:

1. $70-80 \%$ of the grain was separated from the straw, and fell through the lower concave into the cleaning unit in the feeding zone. The rest of the $20 / 30 \%$ of grain was separated at the separation zone.

2. The behaviour of the cumulative separated grain in the transverse axial flow threshing unit should be separately analysed in 2 zones: the feeding zone and the separation zone.

3. In the feeding zone $(0-0.8 \mathrm{~m})$, the grain purity before the cleaning unit was quite constant along the threshing unit length. However, in the separation zone $(0.8-1.7 \mathrm{~m})$, the grain purity decreased when the threshing length decreased. Therefore, an increase in concave rod clearance caused a rapid decrease in grain purity. It also caused a raised amount of grain under the lower concave.

4. The cumulative straw increased linearly during the feeding zone. However, it increased rapidly in the separation zone, especially when the concave rod clearance was large. On the other hand, the cumulative undeveloped kernels and other adulterated substances tended to increase linearly.

5. The cleaning unit, assembled with a transverse axial flow threshing unit, should be modified to spread grain from the area under the feeding zone to the separation zone, in order to avoid overload at the feeding zone.

\section{Acknowledgments}

The authors wish to thank 'Applied Engineering for Important Crops of the North East Research Group', and Khon Kaen University (KKU), for all support provided for this research. 


\section{References}

[1] J. Mongkol-Tanatas, "Machinery for rice harvesting process," in 36 Years of Agricultural Machinery. Bangkok, Thailand: Department of Agriculture, 2009, pp. 1-62.

[2] P. I. Miu and H. Kutzbach, "Modeling and simulation of grain threshing and separation in threshing units-Part I," Computers and Electronics in Agriculture., vol. 60, pp. 96-104, 2008.

[3] S. Chuan-udom and W. Chinsuwan, "Threshing unit losses prediction for Thai axial flow rice combine harvester," Agricultural Mechanization in Asia, Africa and Latin America., vol. 40, pp. 50-54, 2009.

[4] S. Chuan-udom and W. Chinsuwan, "Effects of threshing unit feature on threshing unit losses for Thai axial flow rice combine harvesters," Agricultural Mechanization in Asia, Africa and Latin America., vol. 43, pp. 66-71, 2012.

[5] M. Gummert, H. D. Kutzbach, W. Muhlbauer, P. Wacker, and G.R. Quick, "Performance evaluation of an IRRI axial-flow paddy thresher," Agricultural Mechanization in Asia, Africa and Latin America., vol. 23, pp. 47-58, 1992.

[6] P. Kradangnga, A. Sukchareon, N. Suwatanakul, K. Kobayashi, and Y. Goto, "Study on Paddy Grain from Axial Flow Rice Thresher," Kasetsart J., vol. 25 (Nat. Sci. Suppl.), pp. 140-148, 1991.

[7] O.P. Singhal and G.E. Thierstein, "Development of an axial-flow thresher with multi-crop potential," Agricultural Mechanization in Asia, Africa and Latin America., vol. 18, pp. 57-65, 1987.

[8] S. Chuan-udom, "Operating factors of Thai threshers affecting corn shelling losses," Songklanakarin J. of Science and Technology, vol. 35, pp. 63-67, 2013.

[9] S. Chuan-udom and W. Chinsuwan, "Rice harvesting losses due to use of combine harvesters," Thai Society of Agricultural Engineering J., vol. 16, pp. 3-8, 2010. (in Thai).

[10] Z. Zhao, Y. Li, J. Chen, and J. Xu, "Grain separation loss monitoring system in combine harvester," Computers and Electronics in Agriculture, vol. 76, pp. 183-188, 2011.

[11] W. Chinsuwan, N. Pongjan, S. Chuan-udom, and W. Phayom, "Effects of threshing bar inclination and clearance between concave rod on performance of axial flow rice thresher," Thai Society of Agricultural Engineering J., vol. 10, pp. 15-20, 2003. (in Thai).

[12] S. Chuan-udom and W. Chinsuwan, "Effects of concave rod clearance and number of concave bars on threshing performance of a axial flow rice threshing unit for Chainat 1 variety," KKU Research J., vol. 14, pp. 1037-1045, 2009. (in Thai). 